\title{
A MODEL OF ORGANIZING ACTIVITIES FOR TRAINING METACOGNITIVE SKILLS FOR PRIMARY EDUCATION STUDENTS IN MATHEMATICS TEACHING METHODOLOGY COURSES
}

\section{Nga Thi Hoang}

\section{Article History}

Received: December 11, 2019

Accepted: February 15, 2020

Published: March 30, 2020

\section{Keywords}

Metacognition, students, primary education, mathematics teaching
Hai Phong University, Vietnam

Email: hoangthingadhhp@gmail.com

\section{INTRODUCTION}

Metacognition is understood as a person's ability to control their own cognitive processes, including knowledge of cognitive processes and the orientating, monitoring, revising, and evaluating of cognitive activities involved as needed. Metacognition plays a role as a manager who monitors, orients, controls, adjusts and evaluates the ongoing cognitive processes in the mind of the same cognitive subject.

Metacognitive skills can be understood as the ability to consciously control and regulate ongoing learning and thinking processes. A student with good metacognitive skills will know how to select and use metacognitive strategies to monitor, plan, adjust and evaluate his/her activities to achieve learning goals.

Therefore, metacognitive skills have an important role in teaching and learning processes, helping pedagogical students manage their own learning as well as get "metacognition" in their teaching, which means they will be able to plan, control and regularly adjust their teaching to be effective, use metacognitive strategies in teaching and later instruct their pupils to practice them in the future (Hartman, H.J, 2001). The article proposes a model of organizing activities to train metacognitive skills for students of Primary Education in the courses of mathematics teaching methodology.

\section{LITERATURE REVIEW}

The concept of "Metacognition" was first used by American psychologist J. Flavell in 1976 with the definition "Metacognition refers to one's knowledge concerning one's own cognitive processes or anything related to them (...) [and] refers, among other thing, to the active monitoring and consequent regulation and orchestration of these processes..." (Flavell, J.H, 1976). In short, he defined metacognition as "Thinking about thinking, cognition about cognition". He also proposed a model of cognitive monitoring with four main components: Metacognitive knowledge; Metacognitive experiences; Tasks or goals and Strategies or actions (Flavell, J.H, 1976). Flavell's research provided a theoretical framework and created a new, extensive research trend on metacognition.

Brown, A.L (1987) gave out the definition "Metacognition refers to understanding of knowledge, an understanding that can be reflected in either effective use or overt description of the knowledge in question". She divided metacognition into two broad categories: 1) knowledge of cognition, as activities that involve conscious reflection on one's cognitive abilities and activities; 2) regulation of cognition, as activities regarding self-regulatory mechanisms during an ongoing attempt to learn or solve problems (Brown, 1987). This model emphasizes executive processes, stressing the importance of the control of cognition.

Tobias \& Everson (1995) perceived metacognition as a compound of skills and knowledge - knowledge of cognition, monitoring of one's cognitive and learning processes, and control of those processes. Then, they organized these components into a hierarchical model including four steps in order: monitoring knowledge, evaluating learning, selecting strategies and planning, in which monitoring knowledge is a pre-requisite for activating other metacognitive skills. Hence, they created an assessment instrument that focused on the knowledge-monitoring component of metacognition - The Knowledge Monitoring Assessment (KMA) (Sigmund Tobias, Howard T. Everson, 1995). 
Thus, metacognition is a new research trend with capabilities of applying in teaching. However, there has not been specific research on designing models of organizing activities to train metacognitive skills for students of Primary Education.

\section{METHODS AND RESULTS}

\subsection{Research Methodology}

In this article, we use three research methods. First, theoretical research method in which we examine documents (books, textbooks, magazines, topics, thesis, websites and so forth) on innovating teaching methods in universities and training metacognitive skills for students in general and students of primary education in particular. The second method is practical investigation in which we study the situation of training metacognitive skills for students in primary education in courses of mathematics teaching methodology in universities and colleges. Finally, method of summarizing and applying experiences in which we based on the analysis and synthesis of theories and practice to offer solving orientations, propose a model of organizing activities for training metacognitive skills for students of primary education and exemplify the application of this model on teaching the courses of mathematics teaching methodology.

\subsection{Research Results}

\subsubsection{Some basic metacognitive skills to train students}

Brown, A.L. (1978) divided metacognitive skills into: 1) Predicting; 2) Planning; 3) Checking; 4) Monitoring.

Tobias and Everson (1995) in the hierarchical model classified metacognitive skills into monitoring knowledge, evaluating learning, selecting strategies, and planning, in which monitoring knowledge was a pre-requisite for activating other metacognitive skills (Tobias \& Eversong, 1995).

Louca E.P. (2008) perceived metacognitive skills as "conscious control processes such as planning, monitoring of the progress of processing, effort allocation, strategy use and regulation of cognition" (Louca, 2008, p. 7).

In general, according to the researchers, there are many metacognitive skills mentioned such as monitoring knowledge, predicting, selecting strategies, planning, supervising, revising and evaluating. Within the scope of this article, we focus on training the following basic metacognitive skills for students of primary education:

- Monitoring knowledge. This is the most fundamental skill. According to Tobias and Everson (2002), "Monitoring of prior learning process is a fundamental or prerequisite metacognitive process,... If students can not differentiate accurately between what they know and do not know, they can hardly be expected to engage in advanced metacognitive activities such as evaluating their learning realistically, or making plans for effective control of that learning... Learners who accurately differentiate between what has been learned previously and what they have yet to learn are better able to focus attention and other cognitive resources on the material to be learned" (Tobias, Everson, 2002, pp.1).

- Planning is the ability to select appropriate strategies for each task/ situation, identify goals and how to implement them to achieve goals set and the allocation/ organization of resources that affect the learning process.

- Supervising-Revising is a specific skill, demonstrating the role and function of metacognitive skills. It is the ability to supervise someone's thinking and performance, detect problems, mistakes and make reasonable adjustments when needed.

- Evaluating learning, an important metacognitive skill, is a sufficient condition to develop the above skills. It is the ability to review and make judgments about how to implement, use resources, time and make decisions in problem solving. This helps students plan and control their learning better.

3.2.2. A proposed model of organizing activities to train metacognitive skills for students of primary education in courses of Mathematics teaching methodology

\subsubsection{Scientific basis}

Metacognition and cognition are inseparable and have dialectic relationships with each other. Therefore, metacognitive activities are performed in parallel with cognitive activities in problem solving.

Polya (1973) emphasized that an effective problem-solving process consists of 4 broad steps: understanding the problem, devising a plan, carrying out the plan and looking back. However, he did not separate metacognitive activities and cognitive activities in problem solving.

Schoenfeld (1987) pointed out four criteria for solving a problem, namely: - Making sure the whole problem was understood before a solution was tried; - Planning; - Monitoring or supervising everything going on in the process; Allocating resources or deciding what to do, for how long and when that problem worked. These criteria are metacognitive factors to ensure solving problem process is effective and in the right direction. 
Artzt, Armor and Thomas (1992) provided a metacognitive-cognitive framework for analyzing solving problem process of eight steps to separate cognitive and metacognitive activities that take place in problem solving. However, the metacognitive skills have not been shown comprehensively and clearly.

On summarizing studies on metacognition over the years, Xiaodong Lin (2001) drew the conclusion that there were two basic approaches to supporting metacognitive development: 1) Strategy training; 2) Creating a supportive social environment as ways to foster metacognitive activities. Based on the above views, the article suggests the arguments in proposing a model of organizing activities to train metacognitive skills for students as follows: - In learning, to develop metacognition for students, it is necessary to create an operating environment which combine cognitive activities with metacognitive activities, teaching domain knowledge with teaching how to self-regulate activities; - Cognitive activities and metacognitive activities which take place simultaneously when students perform a learning task needs to be clarified to emphasize their functions; - In a learning task, metacognitive activities need to take place concurrently to help cognitive activities in the right direction; metacognitive activities can take place before or after cognitive activities.

\subsubsection{Model of organizing activities for training metacognitive skills for students}

Based on the above mentioned points, we propose the model of organizing activities for training metacognitive skills for students in teaching as follows (see Figure 1):

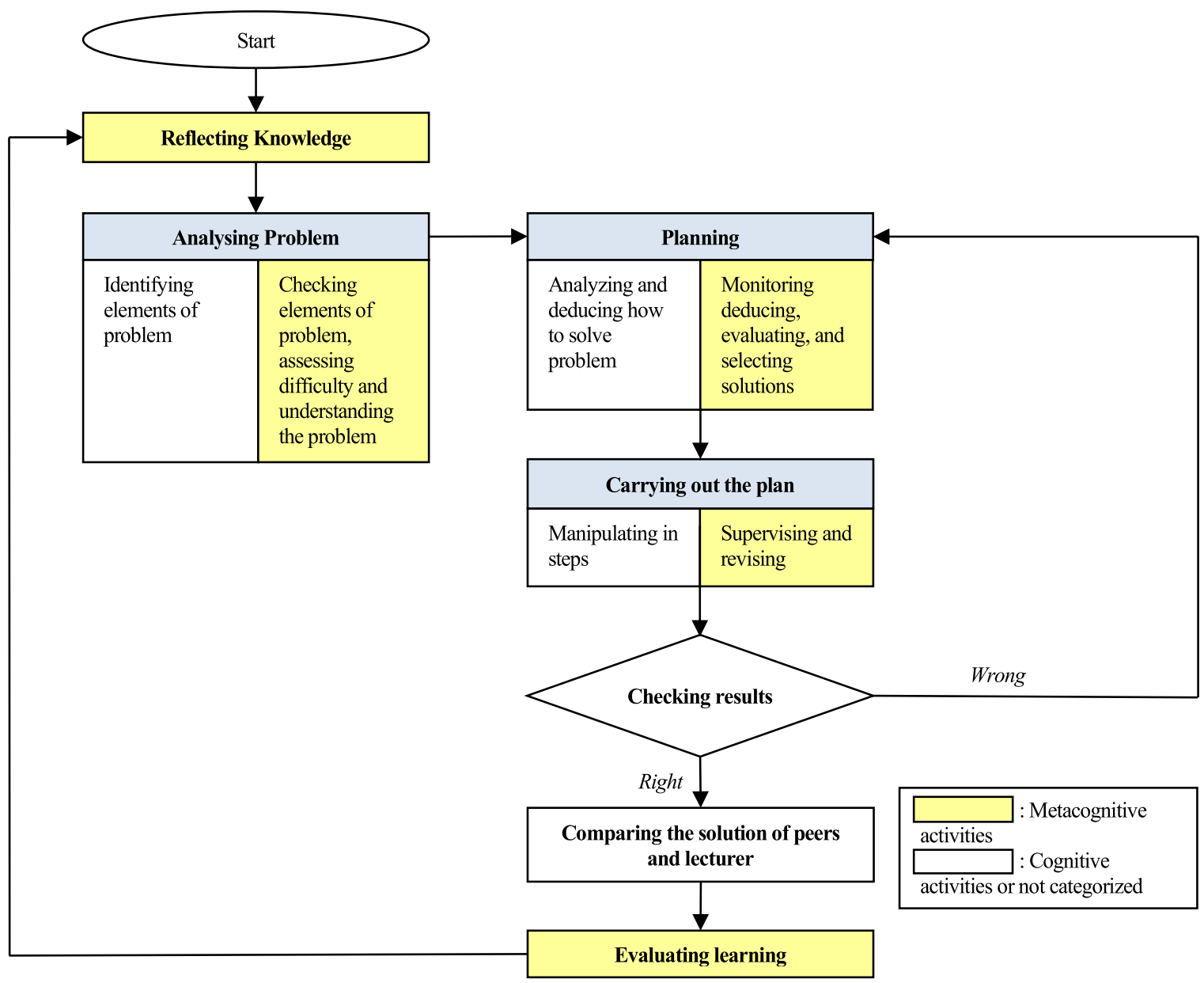

Figure 1. Model of organizing activities for training metacognitive skills for students

This model consists of 7 component activities: Reflecting knowledge, analysing the problem, planning, carrying out the plan, checking results, comparing the solutions of partner and lecturer, and evaluating learning, in which the component metacognitive skills are clearly shown in each activity, and these skills are complementary to each other for development. This model is referred to as MOATMS (Model of Organizing Activities for Training Metacognitive Skills). The following is a detailed discussion of the purpose and the way to implement each component activity in the model. 


\section{Activity 1: Reflecting knowledge (Metacognitive)}

* Purpose: This activity is to develop the monitoring knowledge skill for students through reviewing issues that have been solved, as well as previous problem solving process, comparing them to their predictions of their knowledge and understanding of those problems.

* How to implement:

- Step 1: Learners make their own prediction on the problems that have been solved (lecturer chooses the problems related to the next task).

- Step 2: Lecturer assigns students issues to solve.

- Step 3: Lecturer bases on the results to evaluate the level in which the problem is solved (low, medium, high).

- Step 4: Learners compare solving problem results with their initial predictions. If they are incorrect, learners need to explain the causes and make accurate judgments about their knowledge.

\section{Activity 2: Analyzing the problem}

* Purpose: This activity involves self-assessing the problems being solved to help students reflect their understanding of concepts and solving problems ability, develop monitoring knowledge skills of learners, thereby develop planning skills and strategies selecting skills.

* How to implement:

- Learners use analytical thinking to identify factors of the problem: data (given), request (what to look for), conditions (relationship between data and requirements of the problem (cognitive).

- Learners answer the questions about the extent of understanding the problem and evaluate its difficulty. The number of questions depends on the problem and the extent to which the learners understand the problem (metacognitive).

\section{Activity 3: Planning}

* Purpose: This activity is to develop planning skills for students.

* How to implement: In this activity, students need to identify goals, develop a general plan to achieve the goals set and implement strategies/ manner of actions consistently. To make a specific plan, learners need to search and analyze information related to the problem, consider the disadvantages and advantages and objectives of solving the problem, then give ideas about solutions, models and actions to solve the problem. Finally, students need to review the ideas to see if they are appropriate and arrange them in chronological, important or logical thinking order to formulate action plans.

To do that, teachers need to instruct students to answer the following questions (metacognitive): - What is the goal of solving this problem? - What information is needed to support the problem-solving process? - Does the problem that need solving relate to known issues? - What strategies/ methods can be used to solve the problem? - In those strategies/ methods, which one is more optimal, giving quick results and performing more smoothly? - How can you solve the problem in steps? - How much time is required to perform each step? - What resources or assistance can be used to solve the problem?

\section{Activity 4: Implementing the plan}

* Purpose: This activity aims to train learners the ability to monitor and adjust their learning process.

* How to implement:

- Learners follow the steps and strategies used in Activity 3.

- Learners supervise the progress of implementing. If any conflict or mistake is detected, the learners can stop, contrast with the goal and make a decision to adjust the steps taken and the strategy used. In addition, learners can add or adjust resources and supportive factors in the learning process, remind themselves to concentrate or speed up when necessary to ensure the learning process reaches the target and maintains on schedule (metacognitive).

Activity 5: Checking results (cognitive).

* Purpose: Check the results just obtained. If they are correct, then conclude; if they are not correct, then go back to adjust the plan in Activity 3.

* How to implement: After completing, learners receive and evaluate the results by checking taken steps to see if they are accurate and whether the results meet the conditions.

Activity 6: Comparing the solution with partners and lecturer (not categorized).

* Purpose: Learners compare and contrast problem-solving solutions in order to use the result as the basis for their subsequent assessments. 
* How to implement: Learners observe and listen to the solutions of the lecturer and partners.

Activity 7: Evaluating learning (metacognitive).

* Purpose: This activity aims to give learners an opportunity to look back on the learning process they have just done, find out the reason why doing such activity, what happened during the problem-solving process, etc. help learners find the cause of mistakes related to the process of problem-solving. This helps students develop cognitiveassessing skills and the ability to understand problem-solving process. On the other hand, by reviewing the problemsolving process, learners will develop knowledge monitoring and strategies selecting skills.

* How to implement:

- Learners compare problem solving process with the plan made in activity 3 and give out comments. For example, whether the goals have been achieved or not, whether strategies used are appropriate or should be adjusted, whether there is any other way to solve this problem and so forth.

- Students have to see if there are other ways to solve the problem and compare these with each other to find the optimal solution.

- Students compare with original predictions about the difficulty of the problem and their ability to solve it.

- Students compare and relate to similar issues that have been previously solved, thereby giving general comments about strategies/ approaches.

Note: These activities will initially be instructed and modeled (if necessary) by the lecturer, and then students will gradually get acquainted and do it by themselves. Finally, their metacognitive skills will be formed and developed.

3.2.2.3. Applying the model of organizing activities to train metacognitive skills (MOATMS) for students of primary education in teaching the courses of mathematics teaching methodology

Following is an example to illustrate the application of the above-proposed model into teaching Mathematics Practice in Primary School for students of Primary Education:

Sample exercise: A rectangular garden is surrounded by 80 concrete fences, each fence is 1 meter long. The landlord wants to expand on both sides to get a larger garden with 4 fences of 3 meters long. How can the garden be expanded so that the extension area is the largest? Given that before the expansion, the number of fences running the length of the garden is $3 / 2$ the number running the width.

Lecturers organize activities in MOATMS model to solve the above problem as follows:

\begin{tabular}{|c|c|c|}
\hline Activities & Cognitive & Metacognitive \\
\hline $\begin{array}{l}\text { Reflecting } \\
\text { knowledge }\end{array}$ & & $\begin{array}{l}\text { Students make give comments on } \\
\text { their knowledge of the exercise } \\
\text { format. }\end{array}$ \\
\hline $\begin{array}{l}\text { Analyzing } \\
\text { problem }\end{array}$ & $\begin{array}{l}\text { - Read the exercise. } \\
\text { - Determine the elements of the problem: data, } \\
\text { requirements, relationships between data and factors to } \\
\text { be found. }\end{array}$ & $\begin{array}{l}\text { - Check to see if there is any hidden } \\
\text { relationship between the given } \\
\text { element and the target. } \\
\text { - Assess the difficulty level: the } \\
\text { problem has an "open" situation - } \\
\text { expanding the garden on both sides } \\
\text { but it is not clear which side, so } \\
\text { students should give out all the ways } \\
\text { to expand, calculate the extension } \\
\text { area to find the way for the largest } \\
\text { area. } \\
\text { - Predict all possibilities to solve } \\
\text { problems: It can be solved by the } \\
\text { formula to calculate the area of a } \\
\text { rectangle or by cutting and jigsawing. }\end{array}$ \\
\hline Planning & $\begin{array}{l}\text { - There are } 03 \text { ways to expand the garden: } \\
\text { + On both sides of the garden (both length and width): }\end{array}$ & $\begin{array}{l}\text { Control the direction of deduction: } \\
\text { - What are the ways to expand the } \\
\text { garden? }\end{array}$ \\
\hline
\end{tabular}




$$
3 \mathrm{~m}
$$

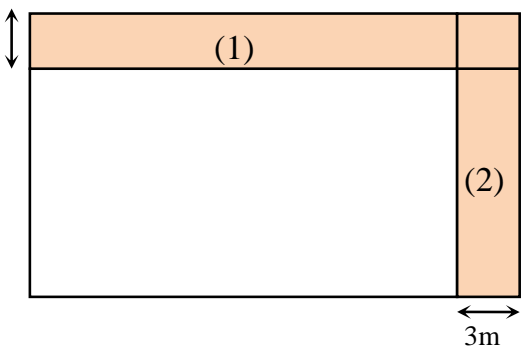

Image 1

+ On both sides of length:

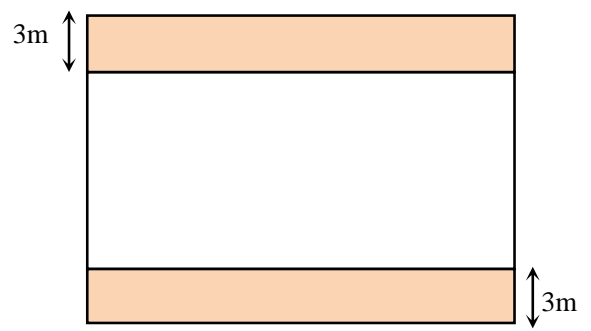

Image 2

+ On both sides of width:

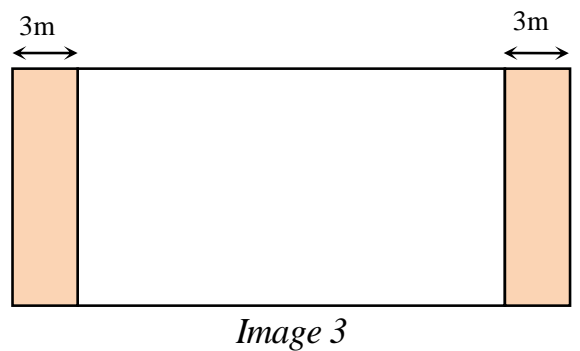

- Need to calculate the area of the extended image or the area of the extension in the possibilities.

- Possibly calculate the length of the edges of the created rectangle, apply the formula to calculate the area of the rectangle to calculate the area of the formed shape, then subtract the area of the original rectangle to be the area of the extension. Or by cutting and jigsawing, the area of the extension can be directly calculated.

- Steps to solve the problem:

+ Step 1: Calculate the length and width of the original image.

+ Step 2: Calculate the length and width of the extended image (or the extension).

+ Step 3: Calculate the area of the expanded image (or the extension)

+ Step 4: Compare the area of the expanded image (or the extension) in the three ways.

+ Step 5: Give conclusions.

There are three ways to expand the garden.

Implementing * The first way: Expanding on both sides of the garden the plan (length and width) (see Image 1). Method 1:
- How to know which extension of the way is the largest?

- In each case, how is the area of the expanded image calculated?

- What are the steps to solve the problem?

- Supervise the inference process and make a decision to choose solutions.

- Supervise the solution steps, review the solution and the results of the calculations (if an error is detected, students will stop to adjust). 
The half of the perimeter of the original garden is: $80: 2=40(m)$

The width of the original garden is:

$40:(2+3) \times 2=16(\mathrm{~m})$

The length of the original garden is: $40-16=24(\mathrm{~m})$

The width of the new garden is: $16+3=19(\mathrm{~m})$

The length of the new garden is: $24+3=27(\mathrm{~m})$

The area of the new garden is: $19 \times 27=513\left(\mathrm{~m}^{2}\right)$

The area of the original garden is: $16 \times 24=384\left(\mathrm{~m}^{2}\right)$

The area of the extension is: $513-384=129\left(\mathrm{~m}^{2}\right)$

Method 2 (jigsawing):

The area of the extension is the sum of the area of the rectangle (1) that is $3 m$ wide and $27 m$ long and the rectangle (2) that is $3 m$ wide and $16 m$ long.

The area of the extension is:

$3 \times 27+3 \times 16=129\left(\mathrm{~m}^{2}\right)$

Method 3 (cutting and jigsawing): Cut the rectangle (2) and then join it into the rectangle (1) (as shown in Image 4):

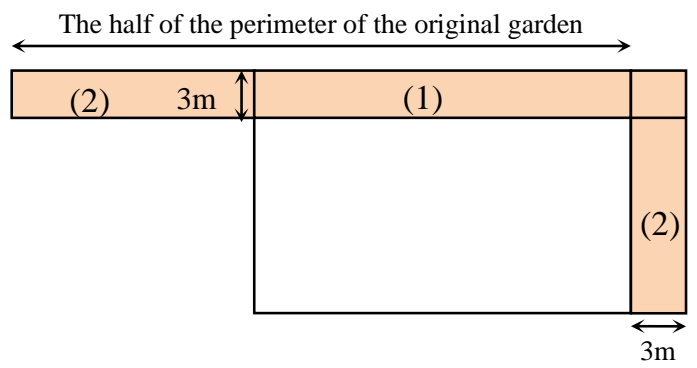

Image 4

In the area of extension equal to the sum of the area of rectangle (1) and (2),

The width is: $3 m$

The length is: $40+3=43(\mathrm{~m})$

The areas of the extension is: $3 \times 43=129\left(\mathrm{~m}^{2}\right)$

* The second way: Extending on both sides of the length (see Image 2).

The extension consists of two rectangles with the same area and the length is $24 m$, the width is $3 m$.

Therefore, the area of the extension is:

$2 \times 24 \times 3=144\left(\mathrm{~m}^{2}\right)$

* The third way: Expanding on both sides of the width (see Image 3).

The extension consists of two rectangles with equal area and the length is $3 \mathrm{~m}$, the width is $16 \mathrm{~m}$.

Therefore, the area of the extension is: $2 \times 3 \times 16=96\left(\mathrm{~m}^{2}\right)$
- Check if there are any other solutions. 


\begin{tabular}{|c|c|c|}
\hline & $\begin{array}{l}\text { Comparing the above ways, it is found that the second } \\
\text { way for the extension has the largest area. }\end{array}$ & $\begin{array}{l}\text { - Compare the ways, give comments } \\
\text { on the most optimal way. }\end{array}$ \\
\hline $\begin{array}{c}\text { Checking } \\
\text { results }\end{array}$ & $\begin{array}{l}\text { - Check arguments and calculations to see if the results } \\
\text { are correct or not. }\end{array}$ & \\
\hline $\begin{array}{l}\text { Comparing } \\
\text { the solutions } \\
\text { of partners } \\
\text { and lecturer }\end{array}$ & \multicolumn{2}{|c|}{ Students present their solutions and compare with each other. } \\
\hline $\begin{array}{l}\text { Evaluating } \\
\text { learning }\end{array}$ & & $\begin{array}{l}\text { - Students consider if the solution } \\
\text { satisfies the goal of the problem or not. } \\
\text { - Students consider if there are any } \\
\text { other ways or not. } \\
\text { - Students make comments on the } \\
\text { "open" problem and how to solve it. } \\
\text { - Students make the assessment of } \\
\text { their problem-solving ability. }\end{array}$ \\
\hline
\end{tabular}

\section{DISCUSSION AND CONCLUSION}

The model of organizing activities for training metacognitive skills proposed in this article can be applied in many different teaching activities: teaching theory, teaching problem solving or practicing. Based on the type of activity, lecturer may be flexible in a number of steps of the model (which may be reduced or integrated together). When organizing teaching activities under this model, initially teachers need to have specific instructions for students to perform each component activity and offer an opportunity for students to form a habit of monitoring and adjusting their learning process. When the frequency of repetition is adequate, questions or reminders will be transformed into the learner. At that time, teachers only need to assign tasks rather than give instructions while students automatically ask questions. This means students' skills for self-monitoring and adjusting the learning process would have been established.

\section{REFERENCES}

Anuradha Sindhwani \& Manoj Kumas Sharma (2013). Metacognitive Learning skills. Educationnia Confab, 2(4).

Artzt, A. \& Armour-Thomas, E. (1992). Development of a cognitive-metacognitive framework for protocol analysis of mathematical problem solving in small groups. Cognition and Instruction, 9(2), 137-175.

Brown, A. L. (1978). Knowing when, where, and how to remember. A problem of metacognition. In R. Claser (Ed.), Advances in Instructional Psychology, 1, 77-165, Lawrence Erlbaum Associates, Inc., Hillsdale, New Jersey.

Brown, A. L. (1987). Metacognition, executive control, self-regulation and other more mysterious mechanisms. In F. E. Weinert \& R. H. Kluwe (eds), Metacognition, Motivation and Understanding, chapter 3, 65-116, Lawrence Erlbaum Associates, Inc., Hillsdale, New Jersey.

Flavell, J. H. (1976). Metacognitive aspects of problem solving. In L. B. Resnick (ed.). The Nature of Intelligence, chapter 12, 231-235, Lawrence Erlbaum Associates, Hillsdale, New Jersey.

Flavell, J. H. (1979). Metacognition and cognitive monitoring: a new area of cognitive developmental inquiry. American Psychology, 34(10), 906-911.

Hartman, H. J. (2001b). Teaching metacognitively. In H.J. Hartman (ed). Metacognition in Learning and Instruction: Theory, Research, and Practice, chapter 8, 149-169, Kluwer Academic Publishers, Dordrecht, The Netherlands.

Livingston, J. A. (2003). Metacognition: An overview. The Educational Resources Information Center.

Louca E. P. (2008). Metacognition and Theory of mind. Cambridge Scholars, UK.

Polya, G. (1973). How to Solve It: A New Aspect of Mathematical Method, $2^{\text {nd }}$ edition. Princeton, NJ: Princeton.

Sigmund Tobias \& Howard T. Everson (1995). Development and validation of an objectively scored measure of metacognition. Paper presented at the Annual Meeting of the American Education Research Association, San Francisco.

Sigmund Tobias \& Howard T. Everson (2002). Knowing what you know and what you don't: further research on metacognitive knowledge monitoring. College Entrance Examination Board, New York.

Xiaodong Lin (2001). Designing metacognitive activities. Educational Technology Research and Development, 49(2), 23-40. 